Revista Eletrônica de Direito Processual - REDP.

Rio de Janeiro. Ano 11. Volume 18. Número 1. Janeiro a Abril de 2017

Periódico Quadrimestral da Pós-Graduação Stricto Sensu em Direito Processual da UERJ

Patrono: José Carlos Barbosa Moreira. ISSN 1982-7636. pp. 278-301

www.redp.uerj.br

\title{
POSSIBILIDADES E LIMITES PARA A TUTELA DA INTIMIDADE E DA \\ PRIVACIDADE ENQUANTO DIREITOS META-INDIVIDUAIS ${ }^{1}$
}

\section{POSSIBILITIES AND LIMITS FOR THE PROTECTION OF PRIVACY AND INTIMACY AS META-INDIVIDUAL RIGHTS}

\author{
Humberto Dalla Bernardina de Pinho \\ Professor Titular de Direito Processual Civil da UERJ. \\ Professor Adjunto no IBMEC/RJ. Promotor de Justiça no \\ Estado do Rio de Janeiro. humbertodalla@gmail.com
}

Luiz Augusto Castello Branco de Lacerda Marca Professor da UNISUAM. Mestre em Direito na UCP.

\begin{abstract}
RESUMO: O objetivo deste artigo é destacar a evolução histórica do direito fundamental à vida privada, desde sua noção originária como direito de exclusão, até a sua compreensão como o direito à autodeterminação informativa, através do controle acerca das informações essenciais sobre si mesmo. O texto apresenta ainda a evolução da tutela metaindividual dentro do contexto do ordenamento jurídico brasileiro e a sua possível utilização como mecanismo garantidor da proteção efetiva da vida privada.
\end{abstract}

PALAVRAS-CHAVE: Privacidade - autodeterminação informativa- tutela metaindividual

ABSTRACT: The objective of this article is to highlight the historical evolution of the fundamental right to privacy, from its original notion as a right of exclusion, until its understanding as the right to informational self-determination through control over the essential information about oneself. The text also presents the evolution of metaindividual tutelage within the context of the Brazilian legal system and its possible use as a guarantor of effective protection of private life.

\footnotetext{
${ }^{1}$ Artigo recebido em 14/03/2017 e aprovado em 17/04/2017.
} 
KEYWORDS: Privacy - informational self-determination - metaindividual tutelage

SUMÁRIO: 1. Considerações Iniciais. 2. Os Direitos da Personalidade. Premissas Conceituais. 3. A intimidade e a privacidade; conceituação tradicional. 4. O conceito contemporâneo da intimidade e da privacidade; o direito à autodeterminação informativa. 5. Evolução Normativa da Tutela Coletiva no Brasil: a tutela dos direitos metaindividuais. 6. A nova concepção da jurisdição coletiva no CPC/2015: a tutela dos direitos pluri-individuais. 7. Considerações conclusivas: a viabilidade da proteção da vida privada por meio da tutela dos direitos pluri-individuais assim previstos no CPC/2015. 8. Referências Bibliográficas

\section{Considerações Iniciais}

O último século de evolução humana representou um inegável aumento de complexidade nas relações sociais que marcam o mundo contemporâneo. Neste sentido, o incremento de novas tecnologia de captação e transmissão de dados, associado à popularização de uma "convivência em rede" levam a uma grande fragilização do indivíduo, diante de um paradoxo crescente: a exposição cada vez mais constante da vida privada inviabiliza quase que por completo a preservação de dados e informações pessoais, ao mesmo tempo em que cresce a importância destes para a composição de um perfil identitário dos indivíduos.

Nas palavras de Rodotà2 "nós somos as nossas informações, que nos definem, nos classificam, nos etiquetam. É necessário controlar a circulação das informações e saber quem as usa, na verdade, é um poder em si mesmo".

Este empoderamento representado pelo controle acerca das informações e dados, alguns deles de extrema significância pessoal (sensitive data) se torna mais e mais uma utopia diante do quadro apresentado atualmente, levando mesmo ao questionamento de

\footnotetext{
${ }^{2}$ RODOTÀ, Stefano. A vida na sociedade da vigilância. Trad. Maria Celina Bodin de Moraes. Rio de Janeiro: Renovar, 2008, p. 16.
} 
Revista Eletrônica de Direito Processual - REDP.

Rio de Janeiro. Ano 11. Volume 18. Número 1. Janeiro a Abril de 2017

Periódico Quadrimestral da Pós-Graduação Stricto Sensu em Direito Processual da UERJ

Patrono: José Carlos Barbosa Moreira. ISSN 1982-7636. pp. 278-301

www.redp.uerj.br

alguns autores como Teixeira a questionar se "ainda existe privacidade no mundo de hoje" $" 3$ ?

O questionamento é pertinente, dada a dificuldade em conferir uma dimensão conceitual clara à ideia de vida privada, em virtude da multiplicidade de abordagens possíveis.

Este paper se propõe a enfrentar os seguintes questionamentos: É viável (ou mesmo desejável) delimitar um contorno preciso do que seja a esfera privada dos indivíduos? Falar em vida privada compreenderia a percepção de intimidade e privacidade como fenômenos distintos, ou ambos poderiam ser reduzidos a um único significado? Seria possível conferir à esfera privada proteção adequada através das ferramentas de tutela coletiva hoje existentes?

Para tanto, o estudo inicia com um panorama conceitual básico dos direitos da personalidade, para posteriormente abordar a intimidade e a privacidade, promovendo um estudo crítico de seus conceitos clássico e contemporâneo. Após traçar a variação histórica do alcance atribuído a tais direitos, pretende-se enfrentar a problemática do adequado tratamento processual apto a garantir sua defesa em juízo, diante da sistemática clássica da tutela coletiva e dos novos instrumentos de proteção dos direitos pluriindividuais previstos no $\mathrm{CPC} / 2015$.

\section{Os Direitos da Personalidade. Premissas Conceituais}

Os direitos da personalidade podem ser definidos como os direitos subjetivos que protegem o conjunto de atributos inerentes à condição humana ${ }^{4}$, permitindo ao indivíduo desenvolver suas potencialidades em busca de seu projeto existencial de vida digna.

\footnotetext{
${ }^{3}$ Daniele Chaves TEIXEIRA. Breves Considerações sobre a privacidade da pessoa notória no espaço público. In: TEPEDINO, Gustavo; FACHIN, Luiz Edson et. all. Diálogos sobre Direito Civil, v. III. Rio de Janeiro: RENOVAR, 2012, p. 203.

${ }^{4} \mathrm{O}$ conceito supra parte da premissa que limita a o objeto dos direitos da personalidade às pessoas naturais. De advertir-se que esta posição não é pacífica em doutrina, havendo doutrina que estende seu alcance para as pessoas jurídicas. Por todos, cf. GAGLIANO, Pablo Stolze; FILHO, Rodolfo Pamplona. Novo Curso de Direito Civil, v. 1. 16a ed., São Paulo: Saraiva, 2014, pp. 192-193. A controvérsia, por ser estranho ao objeto deste trabalho, não será aqui enfrentada.
} 
Revista Eletrônica de Direito Processual - REDP.

Rio de Janeiro. Ano 11. Volume 18. Número 1. Janeiro a Abril de 2017

Periódico Quadrimestral da Pós-Graduação Stricto Sensu em Direito Processual da UERJ

Patrono: José Carlos Barbosa Moreira. ISSN 1982-7636. pp. 278-301

www.redp.uerj.br

São direitos que compõem a construção de um perfil identitário de seus titulares, considerados como seres singulares, únicos em suas individualidades e aspirações, e, portanto, não suscetíveis de ser instrumentalizados a nenhum fim.

Neste sentido, parte da doutrina $^{5}$ considera-os como direitos humanos, aplicáveis às relações inter privatos, angularizados por uma perspectiva individual. A relevância de tais direitos é tamanha que, uma vez hipoteticamente suprimidos - ou inviabilizados -, retirariam de todos os demais o significado, na medida em que não permitiriam o pleno desenvolvimento da personalidade humana, necessário para a plena fruição dos outros direitos ${ }^{6}$.

Em doutrina pátria, FARIAS os apresenta como reconhecimento da "proteção jurídica avançada da pessoa", decorrentes de sua própria dignidade ${ }^{7}$.

Depreende-se das contribuições doutrinárias supra que os direitos da personalidade são instrumentos realizadores da proteção à dignidade da pessoa humana, valor maior do ordenamento brasileiro. Dentro desta perspectiva, muito embora não haja que se falar em uma tipicidade estrita de tais direitos (dado que estabelecer uma tipificação numerus clausus equivaleria a restringir o próprio ser humano, o qual se encontra em constante expansão), importante se faz tentar estabelecer uma conceituação precisa de alguns dos aspectos da personalidade humana protegidos pelo legislador.

\section{A intimidade e a privacidade; conceituação tradicional}

A primeira tentativa conceitual da privacidade ocorreu nos EUA, tendo como antecedente fático o caso envolvendo a atriz Marian Manola, fotografada em trajes menores enquanto encenava a peça Castles in The Air (situação que provocou o processo “Manola VS Myers”, julgado pela Suprema Corte de Nova York em 1890).

\footnotetext{
${ }^{5}$ Por todos, SCHREIBER, Anderson. Direitos da Personalidade. São Paulo: ATLAS, 2011, p. 12.

${ }^{6}$ Neste sentido, encontramos as seguintes palavras de Adriano DE CUPIS: "Existem direitos sem os quais a personalidade restaria uma atitude completamente insatisfeita, privada de qualquer valor concreto; direitos desacompanhados dos quais os outros direitos subjetivos perderiam qualquer interesse para o indivíduo: a ponto de chegar-se a dizer que, se esses não existissem, a pessoa não seria mais a mesma. São esses os chamados direitos essenciais" DE CUPIS, Adriano. Os Direitos da Personalidade. Trad. Afonso Celso Furtado Rezende. 2aed. São Paulo: Quórum, 2008, pp. 18-19.

7 "Com esta perspectiva, os direitos da personalidade - ultrapassando a setorial distinção emanada da histórica dicotomia direito público e privado - derivam da própria dignidade reconhecida à pessoa humana para tutelar os valores mais significativos do indivíduo, seja perante outras pessoas, seja em relação ao Poder Público. Com as cores constitucionais, os direitos da personalidade passam a expressar o minimum necessário e imprescindível à vida com dignidade". FARIAS, Cristiano Chaves de; ROSENVALD, Nelson. Direito Civil: Teoria Geral. $9^{a}$ ed. Rio de Janeiro: 2011, p. 150.
} 
Revista Eletrônica de Direito Processual - REDP.

Rio de Janeiro. Ano 11. Volume 18. Número 1. Janeiro a Abril de 2017

Periódico Quadrimestral da Pós-Graduação Stricto Sensu em Direito Processual da UERJ

Patrono: José Carlos Barbosa Moreira. ISSN 1982-7636. pp. 278-301

www.redp.uerj.br

O caso deu origem a artigo publicado por WARREN e BRANDEIS na Harvard

Law Review, intitulado “The Right to Privacy”, no qual a privacidade é concebida como o "direito a ser deixado só", compreendido como parte do "direito a aproveitar a vida", cuja proteção excederia a mera proteção da existência físico-biológica ${ }^{8}$.

O texto, escrito a fins do séc. XIX, antevia a necessidade de estabelecer a proteção do indivíduo, em seus momentos de reclusão, ou em seu seio familiar, sendo concebida como um direito de exclusão diante do risco de danos proporcionado pelas tecnologias, cada vez mais invasivas, que permitiam perpassar os necessários espaços de vida doméstica, bem como a postura excessivamente intrusa da imprensa ${ }^{9}$.

Para os autores, o direito à privacidade encontraria limites no interesse público na divulgação de informações a respeito de seu titular, ou no consentimento prestado pelo mesmo. De notar que, em sua visão a veracidade dos fatos informados, ou a ausência de malícia não constituem permissivos para a violação ao referido direito.

KONDER demonstra que, sob sua coloração original, o direito à privacidade "tinha como corolários a tutela da imagem; o sigilo profissional, de comunicações e bancário; e a inviolabilidade de domicílio. A principal ameaça a esse direito era identificada na imprensa, que começava a ganhar destaque na sociedade civil" ${ }^{10}$.

O referido autor aponta, na concepção original do direito à privacidade, aspectos característicos do direito liberal-burguês moderno, a saber, a individualidade, o viés patrimonialista e o viés voluntarista.

\footnotetext{
${ }^{8}$ Neste sentido, a seguinte passagem da obra: "Gradually the scope of these legal rights broadened; and now the right to life has come to mean the right to enjoy life, - the right to be let alone; the right to liberty secures the exercise of extensive civil privileges; and the term "property" has grown to comprise every form of possession - intangible, as well as tangible". BRANDEIS, Louis D.; WARREN, Samuel D. The right to privacy. Harvard Law Review, Cambridge, v. IV, n. 5, 15 dec. 1890. Disponível em: http://readingnewengland.org/app/books/righttoprivacy/?l=righttoprivacy. Acesso em: 27 fev. 2017. p. 01.

9 "Recent inventions and business methods call attention to the next step which must be taken for the protection of the person, and for securing to the individual what Judge Cooley calls the right "to be let alone". Instantaneous photographs and newspaper enterprise have invaded the sacred precincts of private and domestic life ; and numerous mechanical devices threaten to make good the prediction that "what is whispered in the closet shall be proclaimed from the house-tops." For years there has been a feeling that the law must afford some remedy for the unauthorized circulation of portraits of private persons; and the evil of invasion of privacy by the newspapers, long keenly felt, has been but recently discussed by an able writer" Op. cit., p.02.

${ }^{10}$ Cf. KONDER, Carlos Nelson. Privacidade e corpo: convergências possíveis. Pensar (UNIFOR), v. 18, p. 352-398, 2013, disponível em http://ojs.unifor.br/index.php/rpen/article/view/2696/pdf. Acesso em: 27. fev. 2016, p. 357.
} 
Revista Eletrônica de Direito Processual - REDP.

Rio de Janeiro. Ano 11. Volume 18. Número 1. Janeiro a Abril de 2017

Periódico Quadrimestral da Pós-Graduação Stricto Sensu em Direito Processual da UERJ

Patrono: José Carlos Barbosa Moreira. ISSN 1982-7636. pp. 278-301

www.redp.uerj.br

Contudo, em que pesem tais características próprias do pensamento liberalburguês, o reconhecimento da existência de tal direito teria, nas palavras do autor, representado um marco evolutivo, na medida em que promoveu um aspecto emancipatório dos indivíduos.

No mesmo sentido, RODOTÀ reforça o caráter individual-patrimonialista do direito à privacidade em seu nascedouro. Tal concepção retirou-lhe qualquer suposta característica de jusnaturalismo, conferindo-lhe caráter essencialmente individualista, cujos instrumentos protetivos pautaram-se na tutela da propriedade ${ }^{11}$.

Dessa forma, a privacidade não foi concebida como um "direito humano", cujo fundamento residia em algum aspecto comum a todas as pessoas, mas antes como um direito de índole exclusivista (como sói ser o direito de propriedade), preferencialmente exercido dentro do espaço do domínio privado, de modo que somente poderia ser verdadeiramente fruído por aquele que fosse proprietário.

A percepção norte-americana do "right to be left alone" não estabeleceu diferenças conceituais entre a privacidade e a intimidade, diversamente da doutrina e jurisprudência alemãs, precursoras da teoria dos três graus (esferas) de proteção da privacidade $^{12}$.

De modo aproximado, SARLET, em que pese adotar o termo privacidade numa significação mais abrangente (por entender que a fluidez das diversas esferas da vida privada prejudicaria uma delimitação precisa das fronteiras entre a privacidade e a intimidade), reconhece que a redação do texto constitucional brasileiro impôs uma

\footnotetext{
11 "Em um nível social e institucional, portanto, o nascimento da privacidade não se apresenta como a realização de uma exigência "natural" de cada indivíduo, mas como a aquisição de um privilégio por parte de um grupo. Não é por acaso que seus instrumentos jurídicos de tutela foram predominantemente modelados com base naquele característico do direito burguês por excelência, a propriedade; e que exigências análogas àquelas que a burguesia fez valer ou não foram reconhecidas em qualquer medida à classe operária ou o foram somente mais tarde, através de instrumentos jurídicos completamente diferentes (por exemplo, a tutela da personalidade nas fábricas)". RODOTÀ, Stefano. A vida na sociedade da vigilância. Trad. Maria Celina Bodin de Moraes. Rio de Janeiro: Renovar, 2008, p. 27.

${ }^{12}$ Sobre a estrutura da doutrina alemã acerca das esferas de proteção à vida privada, encontramos Leonardo GRECO: "O primeiro grau diz respeito ao intangível, o indisponível, insuscetível de ponderação, porque sem ele não há respeito à dignidade humana; o segundo grau correspondente a relações e vínculos de identificação pessoal do seu titular com outros sujeitos da comunidade, estando sujeito à ponderação, podendo ser sacrificado em benefício de valores ou interesses superiores; o terceiro grau, decorrente das relações do sujeito com outras pessoas da comunidade que, embora não sejam públicas, não lhe atribuem uma identidade particular, mas correspondem a relações comuns entre pessoas de um determinado grupo social, em que o conteúdo objetivo da comunicação sempre prevalece sobre qualquer interesse individual" GRECO, Leonardo. Limitações Probatórias. In: MIRANDA NETTO, Fernando Gama de; MEIRELLES, Delton Ricardo Soares. Direito Processual em Debate. Niterói: Editora da UFF, 2011, p. 65.
} 
Revista Eletrônica de Direito Processual - REDP.

Rio de Janeiro. Ano 11. Volume 18. Número 1. Janeiro a Abril de 2017

Periódico Quadrimestral da Pós-Graduação Stricto Sensu em Direito Processual da UERJ

Patrono: José Carlos Barbosa Moreira. ISSN 1982-7636. pp. 278-301

www.redp.uerj.br

diferenciação entre os conceitos de privacidade - ligada aos acontecimentos atinentes as relações pessoais das pessoas em geral- e intimidade - voltada à proteção da esfera mais íntima da vida do indivíduo ${ }^{13}$.

O festejado autor também remete à doutrina alemã das esferas de proteção à vida privada, muito embora a entenda insuficiente em razão da dificuldade em emprestar-lhe um sentido bem definido ${ }^{14}$.

A teoria das esferas alemã reparte assim a vida privada em camadas, das quais a intimidade corresponderia ao core do referido direito fundamental, voltada para a proteção do self, do indivíduo-em-si.

As relações particulares, por sua vez, entre os indivíduos de um círculo limitado de pessoas (o núcleo familiar, o grupo de amigos, as relações profissionais sigilosas) constituiriam a privacidade, podendo ser ponderadas com outros valores, tais como o interesse público, sendo passíveis de sofrer restrições in concreto.

Muito embora este trabalho comungue da visão que identifica a intimidade com as situações de isolacionismo absoluto (e.g, o diário no qual se registrem pensamentos, a "caixa de e-mails", os sites que contenham informações estritamente pessoais, como dados bancários e resultados de exames médicos) e a privacidade com as relações pessoais de caráter restrito, às quais não se deseja conferir publicidade ampla (e.g., as relações familiares, as profissionais que envolvam sigilo -tais quais a relação médicopaciente, advogado-cliente-, a confissão religiosa e a correspondência por cartas, faxes, e-mails, ou a conversa telefônica), não parece adequado estabelecer entre ambas uma relação de "graus de proteção".

Tal raciocínio tenderia a enfraquecer a proteção a situações privadas, ao passo em que estabeleceria uma superproteção injustificável às situações de foro íntimo. Parece-nos que melhor raciocínio está em considerar ambos os fenômenos -intimidade e

\footnotetext{
${ }^{13}$ SARLET, Ingo, MARINONI, Luiz Guilherme, MITIDIERO, Daniel. Curso de Direito Constitucional. $3^{\mathrm{a}}$ ed. São Paulo: RT, 2014, p. 407.

14 “A noção, desenvolvida pela doutrina e pela jurisprudência constitucional alemã, de que se podem, no âmbito do direito à privacidade, distinguir três esferas (a assim chamada teoria das esferas), uma esfera íntima (que constitui o núcleo essencial e intangível do direito à intimidade e privacidade), uma esfera privada (que diz com aspectos não sigilosos ou restritos da vida familiar, profissional e comercial do indivíduo, sendo possível uma ponderação em relação a outros bens jurídicos) e uma esfera social (onde se situam os direitos à imagem, e à palavra, mas não mais a intimidade e a privacidade), tem sido criticada como insuficiente para dar conta da diversidade de casos que envolvem a proteção da vida privada, por mais que se possa servir de referencial importante - mas não rígido- para a distinção das diversas situações concretas e seu enquadramento no âmbito de proteção do direito" Op. cit., p. 408.
} 
Revista Eletrônica de Direito Processual - REDP.

Rio de Janeiro. Ano 11. Volume 18. Número 1. Janeiro a Abril de 2017

Periódico Quadrimestral da Pós-Graduação Stricto Sensu em Direito Processual da UERJ

Patrono: José Carlos Barbosa Moreira. ISSN 1982-7636. pp. 278-301

www.redp.uerj.br

privacidade - como espécies de um gênero maior - vida privada -, sendo direitos

fundamentais de existência autônoma, gozando de proteção individualizada e possuindo, cada qual, um núcleo rígido insuscetível de ponderação/restrição, e uma esfera passível de ceder diante de interesses que se mostrem superiores à luz do caso concreto.

\section{4. $O$ conceito contemporâneo da intimidade e da privacidade; o direito à}

\section{autodeterminação informativa}

Importantíssima virada conceitual é apresentada pelo trabalho de RODOTÀ, intitulado A vida na sociedade de vigilância - A privacidade hoje. O estudo apresentado pelo professor italiano reconceitua a privacidade ${ }^{15}$, que passa a ser concebida como o direito ao controle das informações acerca de si próprio, conforme se verá infra.

RODOTÀ - tal qual o fizeram WARREN e BRANDEIS, a fins do séc. XIX -, aponta a inovação tecnológica ligada à comunicação, captação e circulação de dados como responsável por um novo paradigma para a proteção de direitos, tornando insuficientes (ou mesmo superadas) as definição jurídicas até então existentes.

O incremento tecnológico, agregado a interesses públicos e privados, permite um aumento exponencial de coleta e armazenamento de dados, impondo uma pluralidade de enfoques na proteção à privacidade, que pode encontrar-se ameaçada por políticas públicas de segurança totalitárias, bem como por interesses mercadológicos ${ }^{16}$.

A ampliação da ideia de vida privada, nas palavras de TEPEDINO, passa a ser o contraponto do significativo aumento das ameaças proporcionadas pelo atual estágio de desenvolvimento tecnológico,e as tentativas de justificar uma postura invasiva da esfera íntima, sob diversos argumentos ${ }^{17}$. Infindáveis são os exemplos de distorções

\footnotetext{
${ }^{15} \mathrm{O}$ autor utiliza a expressão "privacidade", como compreensiva também da ideia de intimidade, posição da qual se discorda, conforme anteriormente mencionado neste paper. Contudo, seguir-se-á neste tópico a denominação adotada pelo autor.

16 "É bem evidente, de fato, que o enorme aumento da quantidade de informações pessoais coletadas por instituições públicas e privadas visa sobretudo a dois objetivos: a aquisição dos elementos necessários à preparação e gestão de programas de intervenção social, por parte dos poderes públicos, e o desenvolvimento de estratégias empresariais privadas; e o controle da conformidade dos cidadãos à gestão política dominante ou aos comportamentos prevalecentes. Evocar a defesa da privacidade assume portanto significados diversos, dependendo de qual seja o objetivo perseguido através da coleta de informações". RODOTÀ, Stefano. A vida na sociedade da vigilância (trad. Maria Celina Bodin de Moraes). Rio de Janeiro: Renovar, 2008, pp. 28-29.

17 "É notável, como se vê, que a vis expansiva da privacidade no mundo contemporâneo -alimentada pelo manancial de ameaças que se potencializa com o desenvolvimento tecnológico. O crescimento das possibilidades de controle faz com que se tente justificar a "invasão de privacidade"- expressão característica do tempo atual e que bem transmite a ideia da existência de uma "esfera privada"- a cada nova ameaça que
} 
Revista Eletrônica de Direito Processual - REDP.

Rio de Janeiro. Ano 11. Volume 18. Número 1. Janeiro a Abril de 2017

Periódico Quadrimestral da Pós-Graduação Stricto Sensu em Direito Processual da UERJ

Patrono: José Carlos Barbosa Moreira. ISSN 1982-7636. pp. 278-301

www.redp.uerj.br

lesivas à personalidade humana, seja através do uso das assim chamadas "redes sociais", seja através de abusos perpetrados pelo poder público ${ }^{18}$.

Os fatores apresentados supra impõem uma releitura da ideia de vida privada, levando a uma insuficiência de sua roupagem clássica ${ }^{19}$. Assim o "right to be left alone" dá lugar ao "control of information about oneself", conduzindo a um direito à autodeterminação informativa, pautado pelos princípios da correção na coleta e tratamento das informações, finalidade, pertinência, publicidade (referente este especificamente aos bancos de dados que tratem sobre informações pessoais para as quais deva haver um registro público), acesso individual e da segurança física e lógica da coleta de dados.

A conceituação proposta pela obra de RODOTÀ estabelece uma transição de uma visão liberal-burguesa de cunho fortemente individualista-patrimonialista para uma abordagem mais coletivizada, inovando no tratamento teórico dado ao assunto, conforme nos aponta FARIAS ${ }^{20}$, ao afirmar que "de discurso fechado, a privacidade se projeta sobre a coletividade, recuperando sua carga vital e assumindo feições até então desconhecidas" 21 .

\footnotetext{
surja, sejam as mais tangíveis, como o medo do terrorismo, sejam outras menos fundadas no interesse público, como é o caso da intensificação do controle no ambiente de trabalho, calcada em um apelo à produtividade". TEPEDINO, Gustavo, et ali. Código Civil Interpretado conforme a Constituição da República. $2^{\mathrm{a}} \mathrm{ed}, 1^{\mathrm{a}}$ tiragem. Rio de Janeiro: RENOVAR, 2011, p. 21.

${ }^{18}$ Conforme encontramos, dentre outros, em SCHREIBER: "Recorde-se, entre tantos exemplos pitorescos, o recente uso de informações extraídas do Orkut em entrevistas de emprego, ou ainda os abusos perpetrados nos Estados Unidos, na composição do no-fly list (oficialmente Terrorist Watch List), onde foi recentemente incluído o professor emérito da Universidade de Princeton, Walter F. Murphy, sem nenhuma razão aparente além das críticas dirigidas contra o Governo Bush". SCHREIBER, Anderson. Os Direitos da Personalidade e o Código Civil de 2002". In: TEPEDINO, Gustavo, FACHIN, Luiz Edson, Diálogos Sobre Direito Civil. Rio de Janeiro: RENOVAR, 2008, p. 259.

19 "As discussões teóricas e as complexas experiências dos últimos anos demonstram que a privacidade se apresenta, enfim, como noção fortemente dinâmica e que se estabeleceu uma estreita e constante relação entre as mudanças determinadas pelas tecnologias de informação (mas também pelas tecnologias da reprodução, pela engenharia genética) e as mudanças de seu conceito. Uma definição de privacidade como "direito a ser deixado só" perdeu há muito tempo seu valor genérico, ainda que continue a abranger um aspecto essencial do problema e possa (deva) ser aplicada a situações específicas. Na sociedade da informação tendem a prevalecer definições funcionais da privacidade que, de diversas formas, fazem referência à possibilidade de um sujeito conhecer, controlar, endereçar, interromper o fluxo das informações a ele relacionadas. Assim a privacidade pode ser definida mais precisamente, em uma primeira aproximação, como o direito de manter o controle sobre as próprias informações". RODOTÀ, Stefano. A vida na sociedade da vigilância (trad. Maria Celina Bodin de Moraes). Rio de Janeiro: Renovar, 2008, p. 92.

${ }^{20}$ FARIAS, Cristiano Chaves de. Direito Civil- Teoria Geral. $9^{\mathrm{a}}$ ed. Rio de Janeiro: Lumen Juris, 2011, p. 227.

${ }^{21}$ Em sentido aproximado, SCHREIBER ilustra a ampliação histórica do conceito: "A privacidade nasce, é verdade, sob esta insígnia individualista, inspirada pela lógica segregacionista, pela lógica proprietária - "não se entra na propriedade, não se entra na vida privada"-, mas acaba por se converter em um direito mais amplo,
} 
Revista Eletrônica de Direito Processual - REDP.

Rio de Janeiro. Ano 11. Volume 18. Número 1. Janeiro a Abril de 2017

Periódico Quadrimestral da Pós-Graduação Stricto Sensu em Direito Processual da UERJ

Patrono: José Carlos Barbosa Moreira. ISSN 1982-7636. pp. 278-301

www.redp.uerj.br

A “constante expansão" do conceito traça novos desafios a serem enfrentados, conforme ilustra TEIXEIRA ao aludir ao consentimento informado e à "possibilidade de se proteger de julgamentos descontextualizados".

A mesma autora adverte que as variadas definições de vida privada são complementares e atuam em níveis distintos, de certo modo ainda mantendo aplicabilidade, em certas situações, à noção clássica, o que permite concluir pela inexistência de um único conceito suficientemente abrangente de todos os matizes da vida privada na sociedade contemporânea ${ }^{22}$.

Depreende-se das passagens supra que o enfoque da proteção conferida à vida privada pressupõe o estabelecimento de mecanismos processuais adequados a permitir a concreta tutela de tal direito ${ }^{23}$.

Fato inconteste é que a "hipervulnerabilidade" dos direitos da personalidade (particularmente a vida privada, objeto do presente estudo) sujeita-os à necessidade de estabelecer uma proteção especial. Os mecanismos clássicos voltados à tutela processual individual mostram-se insuficientes na medida em que, muitas vezes, o titular do direito à privacidade sequer tem ideia da ocorrência do dano à mesma.

Além disso, em outras ocasiões, uma mesma conduta pode lesar direitos de toda uma coletividade de difícil determinação - ou até mesmo indeterminável -, como nas hipóteses de furto de dados digitais, empresas que oferecem serviços de captação de

\footnotetext{
de caráter social, que abrange hoje especialmente o direito à proteção de dados pessoais. Bem mais sub-reptícia que a intromissão na intimidade doméstica de uma pessoa é a sua exposição ao olhar alheio por meio de dados fornecidos ou simplesmente coletados de forma aparentemente inofensiva. Nas palavras de Danilo Doneda, "nossos dados estruturados de forma a significarem para determinado sujeito uma representação virtual - ou um avatar-, podem ser examinados no julgamento de uma concessão de uma linha de crédito, de um plano de saúde, a obtenção de um emprego, a passagem livre pela alfândega de um país, além de tantas outras hipóteses" SCHREIBER, Anderson. Os Direitos da Personalidade e o Código Civil de 2002". In: TEPEDINO, Gustavo, FACHIN, Luiz Edson, Diálogos Sobre Direito Civil. Rio de Janeiro: RENOVAR, 2008, p. 258.

${ }^{22}$ Em suas palavras: "Vale ressaltar que essas definições de privacidade não são excludentes; pelo contrário, demonstram uma inclusão evolutiva de "novos aspectos de liberdade num conceito ampliado de privacidade", pois as novas definições não superam as mais antigas, considerando que elas são "baseadas em diferentes requisitos e operam em níveis diferentes". TEIXEIRA, Daniele Chaves. Breves Considerações sobre a privacidade da pessoa notória no espaço público In: TEPEDINO, Gustavo, FACHIN, Luiz Edson. Diálogos sobre direito civil, v. III. Rio de Janeiro: RENOVAR, 2012, p. 202.

${ }^{23}$ Esta a advertência do multicitado RODOTÀ: "Outro problema é o de verificar se, independentemente de projetos de reforma legislativa, é possível utilizar os instrumentos jurídicos já existentes não apenas para garantir uma proteção mais extensa à privacidade, mais sobretudo para promover as suas condições básicas". RODOTÀ, Stefano. A vida na sociedade da vigilância (trad. Maria Celina Bodin de Moraes). Rio de Janeiro: Renovar, 2008, p. 31.
} 
Revista Eletrônica de Direito Processual - REDP.

Rio de Janeiro. Ano 11. Volume 18. Número 1. Janeiro a Abril de 2017

Periódico Quadrimestral da Pós-Graduação Stricto Sensu em Direito Processual da UERJ

Patrono: José Carlos Barbosa Moreira. ISSN 1982-7636. pp. 278-301

www.redp.uerj.br

dados para outras empresas ${ }^{24}$ (permitindo traçar assim um perfil acerca dos hábitos de consumo de milhares de usuários de determinado serviço digital), dentre outras situações em que os interesses em jogo envolvam grandes agentes econômicos, ou mesmo órgãos oficiais de grandes nações ${ }^{25}$.

Assim, imperioso que os diversos ordenamentos proporcionem novas técnicas notadamente no campo processual - garantidoras da vida privada.

A seguir, será promovida uma análise da evolução dos mecanismos processuais para a tutela dos direitos metaindividuais a luz do ordenamento jurídico brasileiro para uma posterior compreensão da eficácia dos mesmos como mecanismos hábeis a garantir a proteção da esfera privada dos indivíduos diante do potencial agressor da iniciativa pública e privada.

\section{Evolução Normativa da Tutela Coletiva no Brasil: a tutela dos direitos} meta-individuais

A partir da década de 70, eclodiu o fenômeno da "abertura das portas do Poder Judiciário". Dentro desse contexto, o estudo do melhor mecanismo para lidar com os direitos transindividuais tem se destacado imensamente ${ }^{26}$.

Não por acaso, já que a violação desses direitos acaba levando ao ajuizamento das chamadas macro-lides, ações de "massa", repetitivas, isomórficas ou seriadas, sem dúvidas, as principais responsáveis por impor sobremaneira uma grande carga de trabalho atualmente imposta ao Poder Judiciário.

\footnotetext{
${ }^{24}$ Serviço denominado data mining, consistente na atividade de extrair padrões de comportamento mediante $\mathrm{o}$ cruzamento de dados obtidos quando do acesso a diversas páginas digitais. Na visão de SCHREIBER, "Dessa atividade de prospecção resulta risco significativo à dignidade humana, na medida em que a complexidade do ser humano acaba reduzida a certo perfil comportamental, construído, no mais das vezes, sem qualquer participação ativa do próprio indivíduo" SCHREIBER, Anderson. Direitos da Personalidade. $2^{\mathrm{a}}$ ed. São Paulo: ATLAS, 2013, p. 156.

${ }^{25}$ Causou espécie e comoção o ocorrido na Islândia, país cujo governo cedeu à empresa privada o direito de acesso à dados médicos de sua população, situação descrita por SCHREIBER: "Emblemático é o caso da Islândia. No ano 2000, o governo islandês concedeu à sociedade norte-americana DeCode o direito de projetar, construir e gerir um banco de dados dos históricos médicos da população islandesa, além do direito de cruzar essas informações com os dados genéticos e genealógicos dos islandeses. A iniciativa foi amparada em lei específica, que presumiu o consentimento de todos os cidadãos da Islândia com a formação do banco de dados" SCHREIBER, Anderson. Direitos da Personalidade. $2^{a}$ ed. São Paulo: ATLAS, 2013, p. 173.

${ }^{26}$ PINHO, Humberto Dalla Bernardina de. A dimensão da garantia do acesso à Justiça na jurisdição coletiva. In: PINHO, Humberto Dalla Bernardina de (Org.). Temas contemporâneos de direito processual. Rio de Janeiro: Lumen Juris, 2004, p. 4.
} 
Revista Eletrônica de Direito Processual - REDP.

Rio de Janeiro. Ano 11. Volume 18. Número 1. Janeiro a Abril de 2017

Periódico Quadrimestral da Pós-Graduação Stricto Sensu em Direito Processual da UERJ

Patrono: José Carlos Barbosa Moreira. ISSN 1982-7636. pp. 278-301

www.redp.uerj.br

A insatisfatória regulamentação trazida pelo Código de Defesa do Consumidor, além das controvérsias doutrinárias sobre o assunto, torna ainda mais relevante o papel da jurisprudência para forjar o conceito e a forma da prestação jurisdicional a ser conferida a esses direitos ${ }^{27}$.

Em nosso ordenamento, as dificuldades de plena efetivação da tutela processual dos direitos transindividuais conduziram à elaboração e à discussão de diversos anteprojetos e projetos de Lei com o objetivo de reformular e unificar a atualmente esparsa regulamentação das ações civis públicas. ${ }^{28}$

A seguir, então, examinaremos mais detalhadamente o marco legal da tutela coletiva no Brasil.

Importante se destacar que tradicionalmente o direito processual brasileiro se filia aos ordenamentos de linha romano-germânica, com base em uma concepção fortemente individualistas, refletindo a mentalidade e as necessidades da sociedade daquela época ${ }^{29}$.

Contudo, a crescente massificação das relações interpessoais ${ }^{30}$ forçou, a partir do início da década de 1980, alterações na ordem jurídica processual de nosso país, inspirando-se nos sopros renovadores provenientes do direito norte-americano ${ }^{31}$. Nesse momento, então, começa-se a construir uma efetiva e concreta preocupação com a tutela coletiva lato sensu, dentro do ordenamento processual ${ }^{32}$.

No plano legal, por exemplo, tivemos a instituição da ação civil pública pela Lei

\footnotetext{
${ }^{27}$ ROQUE, Andre Vasconcelos. As ações coletivas no direito brasileiro contemporâneo: de onde viemos, onde estamos e para onde vamos?, in Revista Eletrônica de Direito Processual, vol. XII, 2013, p. 36, disponível em www.redp.com.br, acesso em 20 de dezembro de 2013.

${ }^{28}$ Anteprojeto de Código Brasileiro de Processos Coletivos elaborado no âmbito da Universidade de São Paulo (com a inclusão de propostas de diversos setores públicos, versão janeiro 2007), Anteprojeto de Código Modelo de Processo Coletivo para a Ibero-America, disponível em <http://direitoprocessual.org.br/content/blocos/76/1>, acesso em 15 jun 2013, Projeto de nova Lei da Ação Civil Pública, PL n. ${ }^{\circ}$ 5.139/2009, disponível em < http://www.camara.gov.br/proposicoesWeb/ fichadetramitacao?idProposicao=432485 >, acesso em 15 jun 2013, que encontra-se arquivado, mas que serviu de base para a redação de diversos dispositivos do PLS 282/2011, infelizmente não acolhido pelo Senado Federal em março de 2014.

${ }^{29}$ PINHO, Humberto Dalla Bernardina de. A tutela coletiva no Brasil e a sistemática dos novos direitos. Revista Direito Público, São Paulo v. 2, p. 91-112, 2005.

${ }^{30}$ CAPPELLETTI, Mauro. Fundamental guarantees of the parties in civil litigation: comparative constitutional, international, and social trends, in 25 Stanford Law Review, May, 1973, p. 672, acesso via www.westlaw.com, em 15 de março de 2010.

31 A forte influência do direito norte-americano para o desenvolvimento da tutela coletiva no direito brasileiro é inegável em vista da acentuada proteção aos direitos coletivos a partir das class actions.

32 ZANETI Jr., Hermes. Três Modelos de Processo Coletivo no Direito Comparado: Class Actions, Ações Associativas/Litígios Agregados e o "Processo Coletivo: Modelo Brasileiro", in Processos Coletivos, vol. 5, n. 3, jul a set de 2014, disponível em http://www.processoscoletivos.net/, acesso em 15 de março de 2016.
} 
Revista Eletrônica de Direito Processual - REDP.

Rio de Janeiro. Ano 11. Volume 18. Número 1. Janeiro a Abril de 2017

Periódico Quadrimestral da Pós-Graduação Stricto Sensu em Direito Processual da UERJ

Patrono: José Carlos Barbosa Moreira. ISSN 1982-7636. pp. 278-301

www.redp.uerj.br

$\mathrm{n}^{\mathrm{o}}$. 7.347/85, que teve seu campo de incidência expandido pelas Leis $\mathrm{n}^{\mathrm{o}}$.s 7.853/89,

relativa a interesses coletivos de deficientes, e 7.913/89, sobre responsabilidade por danos a investidores do mercado de valores mobiliários ${ }^{33}$.

No plano constitucional, a promulgação da Constituição Federal de 1988 trouxe consigo a tutela dos interesses transindividuais por meio do mandado de segurança coletivo, além de dar respaldo às já existentes ação popular e ação civil pública ${ }^{34}$.

Após a constituinte, editou-se o Código de Defesa do Consumidor (Lei n. 8.078/90), alterando a Lei da Ação Civil Pública e regulamentando a ação coletiva, em seus arts. 91 a 100.

Posteriormente, tivemos a promulgação da Lei de Improbidade Administrativa (Lei $\mathrm{n}^{\circ} 8.429 / 92$ ), voltada a reprimir atos ilícitos praticados por agentes públicos em suas funções e criando mecanismos para a punição deles e para a devolução ao erário das quantias desviadas de suas finalidades originais ${ }^{35}$; e a Lei ${ }^{\circ}$. $8.884 / 94$, conhecida como

\footnotetext{
33 "A par daqueles fatores de larga amplitude, antes lembrados, a expansão da jurisdição coletiva deveu-se, ainda, a outras concausas, mais específicas: (a) a criação da ação civil pública, pela Lei 7.347/1985, apta a instrumentar valores transcendentes para a coletividade, como deflui do rol constante de seu artigo primeiro, a par da atribuição da colegitimação ativa a diversos atores (Ministério Público, Defensoria Pública, entes políticos, associações, órgãos públicos), em simetria com o ideal de democracia participativa e plural, com isso se prevenindo a concentração excessiva do poder de agir em mãos do Ministério Público, diretriz que, depois, viria recepcionada na CF de 1988 - $\S 1.0$ do art. 129; (b) a recepção da ideia de que nos macro-conflitos a legitimação ativa não tem como fundar-se no critério clássico da "titularidade da pretensão material", como se dá no âmbito da jurisdição singular, mas reclama fundamento diverso, a saber o binômio relevância do interesse - representação adequada, exigindo-se ainda, alguma vez, o concurso da chamada pertinência temática; (c) o advento, em 1988, da vigente Constituição - garantista, abrangente e analítica - impulsionou a jurisdição coletiva, ao positivar ou potencializar os seus meios e instrumentos: ações das associações (art. 5.o, XXI) e dos sindicatos (art. 8.o, III); mandado de segurança coletivo (art. 5.o, LXX); ampliação do objeto da ação popular (art. 5.o, LXXIII); recepção da civil pública (inc. III do art. 129); expansão do rol de ações no controle direto de constitucionalidade: ADIn/ADCon ( $\$ 2.0$ do art. 102); ADPF ( $\$ 1.0$ do art. 102); ação de inconstitucionalidade por omissão ( $\$ 2.0$ do art. 103); ação direta interventiva (art. 34 e incisos); (iv) o advento, em 1990, do Código de Defesa do Consumidor - Lei 8.078 - que, de um lado, trouxe os conceitos dos tipos de interesse metaindividual (difusos, coletivos em sentido estrito, individuais homogêneos - art. 81, parágrafo único e incisos) a que correspondem coisas julgadas de eficácia expandida (art. 103 e incisos); de outra parte, esse Código autorizou o traslado de sua parte processual - arts. 81 a 104 - para o âmbito da ação civil pública (art. 117 da Lei 8.078/1990), assim ensejando a irradiação de importantes contributos, como por exemplo o critério determinativo de competência calcado na dimensão do dano (art. 93 e incisos)". MANCUSO, Rodolfo de Camargo. Da jurisdição coletiva à tutela judicial plurindividual. Evolução da experiência brasileira com as demandas seriais, in Revista de Processo, vol. 237, nov/2014, p. 310.

${ }^{34}$ PINHO, Humberto Dalla Bernardina de. Class actions in Brazilian Law: general aspects. evolution and some controversies. Connecticut Journal of International Law, v. 20, n. 2, 2005, pp. 185/197.

${ }^{35}$ Em 2013 foi publicada a Lei 12.846 que traz a responsabilização administrativa objetiva nos casos de prática de atos contra a administração publica, nacional ou estrangeira. No texto da lei encontram-se descritos os atos por ela regidos, além das sanções e o modo como serão aplicadas. Trata, também, do acordo de leniência que pode ser efetuado entre a Administração Publica e os responsáveis pelos atos descritos na lei, objetivando seus requisitos e efeitos. Ainda, cria o o Cadastro Nacional de Empresas Punidas-CNEP, que reunirá e dará
} 
Revista Eletrônica de Direito Processual - REDP.

Rio de Janeiro. Ano 11. Volume 18. Número 1. Janeiro a Abril de 2017

Periódico Quadrimestral da Pós-Graduação Stricto Sensu em Direito Processual da UERJ

Patrono: José Carlos Barbosa Moreira. ISSN 1982-7636. pp. 278-301

www.redp.uerj.br

Lei Antitruste, visando ao combate das infrações contra a ordem econômica.

Em 1ํ de outubro de 2003, sobreveio a Lei $n^{\circ}$. 10.741, conhecida como Estatuto do Idoso, com o objetivo de proteger pessoas maiores de 60 anos e, dentre outras medidas, possibilitando o ajuizamento da ação civil pública para a defesa de seus interesses.

A Lei Maria da Penha - Lei $n^{\circ}$. 11.340/2006 - que visa a coibir a violência doméstica, também contemplou a tutela coletiva nos art. 26, II, e 37. A Lei $n^{\circ}$. 11.448/2007 modificou a Lei da Ação Civil Pública para legitimar expressamente a Defensoria Pública para propor tais demandas.

A legitimidade da Defensoria Pública veio a ser regulamentada pela LC nº. 132/2009, como será visto adiante. Em 2009, é publicada a nova Lei do mandado de segurança, Lei $n^{\circ}$. 12.016, que disciplina tais ações em esfera individual e coletiva, trazendo, em apenas dois artigos, a regulamentação dos dispositivos constitucionais do art. 5-, LXIX e LXX.

Assim, em relação ao mandado de segurança coletivo, a nova Lei trata apenas da legitimação, objeto e linhas gerais em termos de coisa julgada, litispendência e necessidade de audiência prévia do representante judicial da pessoa jurídica de direito público antes da concessão de liminar.

Criticável, ainda, a limitação do objeto de proteção pelo mandado de segurança coletivo apenas aos direitos coletivos em sentido estrito e aos individuais homogêneos, sem que tal restrição tivesse lastro no texto constitucional.

Ainda em 2009, mais precisamente em abril, é publicado o II Pacto Republicano, tendo como uma de suas metas, a "revisão da Lei da Ação Civil Pública, de forma a instituir um Sistema Único Coletivo que priorize e discipline a ação coletiva para tutela de interesses direitos difusos, coletivos e individuais homogêneos, objetivando a racionalização do processo e julgamento dos conflitos de massa". ${ }^{36}$

Nesse contexto, apresentou-se o Projeto de Lei $n^{\circ}$. 5.139/2009, que pretendia substituir a Lei $n^{\circ}$. 7.347/85 na regulamentação da ação civil pública.

A ideia inicial era a de criar um código brasileiro de processos coletivos, que

publicidade às sanções aplicadas pelos órgãos com base nesta Lei. A Lei foi publicada em 01-08-2013 e entrou em vigor 180 dias depois.

36 Disponível em EE1930A4DC33A8DF216PTBRIE.htm. 
Revista Eletrônica de Direito Processual - REDP.

Rio de Janeiro. Ano 11. Volume 18. Número 1. Janeiro a Abril de 2017

Periódico Quadrimestral da Pós-Graduação Stricto Sensu em Direito Processual da UERJ

Patrono: José Carlos Barbosa Moreira. ISSN 1982-7636. pp. 278-301

www.redp.uerj.br

representaria um significativo avanço à tutela coletiva no Brasil, em sintonia com as evoluções científicas e com a massificação das relações sociais. Contudo, o projeto acabou por não vingar.

Antes de apresentado ao Congresso, o Projeto de Lei $n^{\circ}$. 5.139/2009 teve alterações, em seu texto original, formuladas pela Comissão de Juristas do Ministério da Justiça e, posteriormente, pela Casa Civil da Presidência da República. Então, seguiu para apreciação das Casas Legislativas e para sugestões por parte de instituições que se demonstrarem interessadas.

O relator do projeto, o Deputado Antônio Carlos Biscaia, apresentou, então, parecer substitutivo ao projeto de Lei, em setembro de 2009. Em novembro, foi apresentado o terceiro substitutivo ao projeto de Lei da ação civil pública, incorporando 17 alterações, resultantes das discussões formuladas na Subcomissão Especial instituída para apreciar a matéria.

Em 4 de março de 2010, ocorreu nova alteração do Projeto $n^{\circ}$. 5.139/2009, com o acolhimento de algumas emendas propostas e trazendo ao texto modificações, como a extinção do reexame necessário para as sentenças de improcedência, bem como a tipificação de crime para o retardamento ou omissão injustificados de fornecer dados técnicos essenciais à propositura de uma ação civil pública.

Lamentavelmente, no dia 17 de março de 2010, o projeto acabou rejeitado pela Comissão de Constituição e Justiça da Câmara dos Deputados, em uma votação por maioria, de 17 votos a 14, afirmando a falta de debate e de discussão pública.

Foi, em verdade, um grande retrocesso na regulamentação da tutela coletiva em nossa história. O projeto foi construído a partir do trabalho de diversas entidades representativas, levando em conta trabalhos doutrinários e entendimentos fixados na jurisprudência. Além disso, ele buscava lidar comas polêmicas e as lacunas existentes, por meio, por exemplo, da simplificação das regras de competência e da criação de um cadastro coletivo de ações ${ }^{37}$.

Posteriormente, em 2011, foram apresentados projetos de alteração do Código de Defesa do Consumidor, sendo um deles, o Projeto 282, voltado à tutela coletiva. Foi mais uma esperança de avanço na regulamentação da matéria que acabou rapidamente perdida.

${ }^{37}$ PINHO, Humberto Dalla Bernardina de. Direito Processual Civil Contemporâneo, vol. 1, 5a edição, São Paulo: Saraiva, 2013, p. 815. 
Revista Eletrônica de Direito Processual - REDP.

Rio de Janeiro. Ano 11. Volume 18. Número 1. Janeiro a Abril de 2017

Periódico Quadrimestral da Pós-Graduação Stricto Sensu em Direito Processual da UERJ

Patrono: José Carlos Barbosa Moreira. ISSN 1982-7636. pp. 278-301

www.redp.uerj.br

Em 27 de março de 2013, o Senado Federal concluiu a análise dos Projetos de modernização do CDC e aprovou apenas as regras sobre superendividamento e comércio eletrônico. As disposições do PLS 282, que cuidavam da ação coletiva e das hipóteses de acordos em tais ações acabaram rejeitadas ${ }^{38}$, o que, em última análise, demonstra a posição refratária do Parlamento às ferramentas da tutela coletiva.

Não obstante, em abril de 2014, foi sancionada a Lei $\mathrm{n}^{\circ}$. 12.966, que alterou dispositivos da Lei $\mathrm{n}^{\circ}$. 7.347/85 a fim de incluir como bens tutelados pela ação civil pública a proteção à honra e à dignidade de grupos raciais, étnicos ou religiosos, por meio da inserção do inciso VII ao art. $1^{\circ}$ desse Diploma.

Por fim, parece ter havido consenso no sentido de que a legislação da tutela coletiva não ofertava mais o nível desejável de efetividade ${ }^{39}$ e novos instrumentos tiveram que ser buscados ${ }^{40}$.

\section{A nova concepção da jurisdição coletiva no CPC/2015: a tutela dos direitos}

\section{pluri-individuais}

No exame do tratamento da tutela coletiva no plano legislativo, não se pode deixar de mencionar o Novo Código de Processo Civil.

Inicialmente, é importante ressaltar que o CPC/2015 não trata das ações coletivas. O único dispositivo que previa a possibilidade de conversão de ação individual em ação coletiva (art. 333) foi vetado. Aliás, em muito boa hora ${ }^{41}$, como já tivemos oportunidade

38 http://www.migalhas.com.br/Quentes/17,MI197978,41046-Relatorio+final+do+novo+CDC +e+aprovado ${ }^{39}$ GIDI, Antonio. Class action in Brazil - a model for civil law countries. The American Journal of Comparative Law, v. 51, n. 2, 2003, p. 322.

${ }^{40}$ ROQUE, Andre Vasconcelos. As ações coletivas no direito brasileiro contemporâneo: de onde viemos, onde estamos e para onde vamos?, in Revista Eletrônica de Direito Processual, vol. XII, 2013, p. 36, disponível em www.redp.com.br, acesso em 20 de dezembro de 2013, p. 41.

41 "Começamos pela legitimidade, e este ponto tem especial relevância pois o Projeto é assertivo ao impedir a instauração do incidente ex officio pelo magistrado. Aqui encontramos a chamada legitimidade primária, que toca ao M.P. e à D.P., e a secundária, prevista no $\S 1^{\circ}$, que abrange os "demais legitimados" elencados tanto no art. $5^{\circ}$ da $\mathrm{L} \mathrm{n}^{\circ} 7.347 / 85$, como no art. 82 da Lei $\mathrm{n}^{\circ}$ 8.078/90. (...) Após tratar da legitimidade, o dispositivo estabelece dois grupos de restrições ao uso do instituto. O primeiro grupo vem previsto nos incisos I e II do art. 333, que trazem uma delimitação objetiva da ação individual que poderá ser objeto da conversão. Desta forma, o pedido nesta demanda deve ter "alcance coletivo, em razão da tutela de bem jurídico difuso ou coletivo, assim entendidos aqueles definidos pelo art. 81, parágrafo único, incisos I e II, da Lei no 8.078, de 11 de setembro de 1990, e cuja ofensa afete, a um só tempo, as esferas jurídicas do indivíduo e da coletividade ${ }^{41 ",}$ ou ter "por objetivo a solução de conflito de interesse relativo a uma mesma relação jurídica plurilateral, cuja solução, pela sua natureza ou por disposição de lei, deva ser necessariamente uniforme, assegurando-se tratamento isonômico para todos os membros do grupo". Tal delimitação é reforçada pelo $\S 2^{\circ}$, que impede o usos da conversão para gerar processo coletivo destinado a tutela de direitos individuais homogêneos. Apesar do claro esforço do legislador, ainda há um uso exagerado de conceitos jurídicos indeterminados, restando 
Revista Eletrônica de Direito Processual - REDP.

Rio de Janeiro. Ano 11. Volume 18. Número 1. Janeiro a Abril de 2017

Periódico Quadrimestral da Pós-Graduação Stricto Sensu em Direito Processual da UERJ

Patrono: José Carlos Barbosa Moreira. ISSN 1982-7636. pp. 278-301

www.redp.uerj.br

de ressaltar ${ }^{42}$.

Restaram, apenas, duas referências no texto do Código: a) O art. 139, X que diz incumbir ao juiz, quando se deparar com diversas demandas individuais repetitivas, oficiar o Ministério Público, a Defensoria Pública e, na medida do possível, aos demais legitimados, para, se for o caso, promoverem a propositura da ação coletiva respectiva; e b) $\mathrm{O}$ art. 982, I dispõe que admitido o incidente de resolução de demandas repetitivas (IRDR), o relator deverá determinar a suspensão dos processos pendentes, individuais ou coletivos, em tramitação.

Essa constatação não significa que o CPC/2015 represente um rompimento do com o sistema clássico da tutela coletiva ${ }^{43}$.

Parece, a bem da verdade, que se quis criar um sistema paralelo ${ }^{44}$, que harmonizasse as ações coletivas com as novas ferramentas de julgamento repetitivo, havendo, entre eles, pontos comuns ${ }^{45}$.

\footnotetext{
claro, apenas, que o objeto da demanda deve coincidir com as definições de direito difuso ou de direito coletivo adotadas pelo CDC. O segundo grupo de restrições está no $\S 3^{\circ}$ do mesmo art. 333, que traz três incisos. Nesse passo, não será admitida a conversão se: I - já iniciada, no processo individual, a audiência de instrução e julgamento; ou II - houver processo coletivo pendente com o mesmo objeto; ou ainda III - o juízo não tiver competência para o processo coletivo que seria formado. Com isso, podemos supor que o legislador assume a possibilidade (e o risco) de uma grande transformação no procedimento, mesmo após o despacho saneador, fixação das provas a serem produzidas e, eventualmente, quando já produzidas as provas documental e pericial, o que não me parece razoável". PINHO, Humberto Dalla Bernardina de. Incidente de Conversão da Ação Individual em Ação Coletiva no CPC Projetado: exame crítico do instituto. Artigo publicado na Revista Eletrônica Processos Coletivos, vol. 4, $\mathrm{n}^{\circ} 3,3^{\circ}$ trimestre, p. 23.

${ }^{42}$ PINHO, Humberto Dalla Bernardina de. Considerações sobre o incidente de conversão da ação individual em ação coletiva no projeto do novo CPC. Revista Eletrônica de Direito Processual, v. XIV, ano 8, jul.-dez. 2014, p. 209.

${ }^{43}$ ROQUE, Andre Vasconcelos. As ações coletivas no direito brasileiro contemporâneo: de onde viemos, onde estamos e para onde vamos?, in Revista Eletrônica de Direito Processual, vol. XII, 2013, p. 44, disponível em www.redp.com.br, acesso em 20 de dezembro de 2013.

${ }^{44}$ DIDIER JR, Fredie. ZANETI JR., Hermes. Ações coletivas e o incidente de julgamento de casos repetitivos - espécies de processo coletivo no direito brasileiro: aproximações e distinções, in Revista de Processo, vol. 256, Jun/2016, pp. 211/212.

${ }^{45}$ DIDIER Jr., Fredie. ZANETI Jr. Hermes. Conceito de processo jurisdicional coletivo. Revista de Processo, vol. 229, Mar/2014, São Paulo: Revista dos Tribunais, p. 278.
} 
Revista Eletrônica de Direito Processual - REDP.

Rio de Janeiro. Ano 11. Volume 18. Número 1. Janeiro a Abril de 2017

Periódico Quadrimestral da Pós-Graduação Stricto Sensu em Direito Processual da UERJ

Patrono: José Carlos Barbosa Moreira. ISSN 1982-7636. pp. 278-301

www.redp.uerj.br

Institui-se, assim, um mecanismo novo para a tutela de direitos pluriindividuais ${ }^{46}$, sem alguns problemas crônicos das ações civis públicas ${ }^{47}$.

Essas ferramentas estão previstas no art. 928. São os julgamentos de recursos por amostragem (arts. 1.036-1.041) e o incidente de resolução de demandas repetitivas (arts. 976-987), que visam à pacificação de conflitos envolvendo direitos individuais homogêneos discutidos em múltiplas ações individuais.

\section{Considerações conclusivas: a viabilidade da proteção da vida privada por} meio da tutela dos direitos pluri-individuais assim previstos no CPC/2015

Em que pese a noção de vida privada estar visceralmente ligada aos direitos da personalidade (expressões singulares da diversidade e individualidade humanas), resta claro que o avanço tecnológico característico dos tempos atuais e a própria existência de uma "cultura digital" produzem um contexto causador de extremas dificuldades para a tutela individual da esfera privada.

Considerando especialmente o conceito trazido pela doutrina de Rodotà de autodeterminação afirmativa através do controle dos dados acerca de si mesmo, temos a existência de alguns paradoxos.

Um deles é que, por vezes, o titular do direito à vida privada sequer tem conhecimento da obtenção, por terceiros, dos dados que lhe dizem respeito, o que pode inviabilizar a defesa de seus interesses.

Ademais, por vezes a lesão à esfera privada parte da agressão a interesses de uma coletividade, dentro da qual o titular do direito lesado se inclui, e que, justamente em virtude deste pertencimento, gera repercussões individuais reflexas. Supostos interesses estatais em preservar a segurança nacional também podem conduzir a abusos

\footnotetext{
${ }^{46}$ Para Bruno Dantas, a tutela pluri-individual é "aquela tutela que não é nem a individual clássica, do processo de Tício contra Caio, com direito subjetivo, partes muito bem definidas e legitimidade muito bem delimitada, nem aquela tutela para direitos coletivos stricto sensu. Entre um e outro, o sistema tinha que ter uma sistemática aplicável para aqueles casos que discutem direitos individuais homogêneos. Portanto, o novo código veio para tratar dessa tutela plurindividual, que é o julgamento de casos repetitivos por meio de dois grandes institutos: o julgamento do incidente de resolução de demandas repetitivas e o julgamento de recursos especiais e extraordinários". $\quad$ http://www.conjur.com.br/2016-jul-03/entrevista-bruno-dantas-ministro-tcuprofessor?utm_source=dlvr.it\&utm_medium=twitter, acesso em 03 de julho de 2016.

${ }^{47}$ SIQUEIRA, Tatiana Paula Cruz de. A escalada rumo à valorização do precedente judicial no processo civil brasileiro, in CARNEIRO, Paulo Cezar Pinheiro. GRECO, Leonardo. PINHO, Humberto Dalla Bernardina de. Inovações do CPC/2015, GZ: Rio de Janeiro, 2016, p. 67/99.
} 
Revista Eletrônica de Direito Processual - REDP.

Rio de Janeiro. Ano 11. Volume 18. Número 1. Janeiro a Abril de 2017

Periódico Quadrimestral da Pós-Graduação Stricto Sensu em Direito Processual da UERJ

Patrono: José Carlos Barbosa Moreira. ISSN 1982-7636. pp. 278-301

www.redp.uerj.br

aos direitos individuais à vida privada, pouco havendo o que o indivíduo possa fazer neste sentido ${ }^{48}$.

Diante desse contexto de extrema vulnerabilidade individual, entende-se que a tutela metaindividual se apresenta como um mecanismo garantidor da eficácia deste direito fundamental, na medida em que proporciona mecanismos de tutela mais eficazes e reequilibradores dos interesses em jogo.

A evolução tecno-científica que fortemente caracteriza a sociedade contemporânea, ao mesmo tempo em que proporciona inegáveis benefícios, produz uma série de questionamentos éticos e de novos desafios aos quais cabe ao direito adaptar-se.

Partindo desta premissa, tem-se que a noção de vida privada evoluiu de uma perspectiva tipicamente liberal para uma dimensão social, na qual há um significativo (para não dizer exagerado) grau de controle a respeito de informações pessoais (notadamente os denominados "dados sensíveis"), componentes definidores da identidade pessoal.

Entretanto, a simples oxigenação conceitual do referido direito de modo a atualizá-lo ante as exigências dos novos tempos não basta para torná-lo efetivo diante das incontáveis ameaças e paradoxos capazes de reduzir-lhe a existência concreta.

Urge, assim, repensar sua proteção mediante instrumentos de tutela processual metaindividual, de modo a tornar a defesa de tais interesses concretamente eficaz.

Nesse sentido, não se pode deixar de reconhecer que há um déficit de efetividade dos instrumentos tradicionais, como a ação civil pública. Esse fator, aliado a já referida

\footnotetext{
${ }^{48}$ Parte destes riscos é objeto da advertência de SCHREIBER: Quando a evolução tecnológica permite que o empregador monitore indiscretamente o conteúdo dos emails do seu empregado, quando a fotografia ou a digital de cada cidadão é colhida como etapa necessária do seu ingresso em prédios comerciais, quando cada um de nós passa a receber mensagens publicitárias no telefone celular enviadas por empresas a quem nunca fornecemos nossos dados, é aí que a atuação da ordem jurídica se torna imprescindível para instituir algum controle social sobre práticas que quase distraidamente vão afrontando nossa privacidade e colecionando nossos dados pessoais, sempre em nome de um suposto bem maior, cada vez mais diminuto. Ao revelar que telefonemas e e-mails de centenas de brasileiros, incluindo a Presidente da República, foram monitorados por uma agência norte-americana, o caso Snowden demonstrou como pode ser falacioso o discurso segundo o qual a privacidade deve ceder à segurança pública. Uma vez que a privacidade é rompida, ninguém mais pode dizer se os dados obtidos estão sendo usados realmente para "garantir" a segurança de um país ou, muito diversamente, para favorecer interesses comerciais de concorrentes da Petrobras. Essa é uma característica inerente à privacidade: não se pode aplicá-la apenas às informações que devam justificadamente permanecer privadas. Para avaliar a justificativa, seria necessário conhecer tais informações e isso representaria violação à privacidade por si só". SCHREIBER, Anderson. Biografias, privacidade e indenização. Disponível em: http://www.andersonschreiber.com.br/downloads/biografias_privacidade indenizacao_artigo_carta fore nse.pdf. Acesso em 28.02.2017. p. 01).
} 
Revista Eletrônica de Direito Processual - REDP.

Rio de Janeiro. Ano 11. Volume 18. Número 1. Janeiro a Abril de 2017

Periódico Quadrimestral da Pós-Graduação Stricto Sensu em Direito Processual da UERJ

Patrono: José Carlos Barbosa Moreira. ISSN 1982-7636. pp. 278-301

www.redp.uerj.br

restrição dos órgãos legislativos aos projetos apresentados entre os anos de 2007 e 2012, já indica a necessidade da busca de uma nova ferramenta.

Assim sendo, no CPC de 2015, o modelo antes previsto nos arts. 543-A e B foi aperfeiçoado e aprofundado. O atual art. 1.036 prevê que "sempre que houver multiplicidade de recursos extraordinários ou especiais com fundamento em idêntica questão de direito, haverá afetação para julgamento".

Nesse contexto, se houver uma mesma matéria jurídica reiteradamente tratada em sede recursal, pode se selecionar um recurso excepcional que represente a controvérsia, suspendendo o curso dos demais.

Na ocasião do julgamento, até para tentar legitimar democraticamente a eficácia da tese jurídica a ser fixada, o Código busca garantir a ampla participação dos sujeitos interessados, tantos as partes de processos sobrestados como de órgãos e entidades representando a sociedade civil (CPC/2015, art. 1.038, I).

A afetação do recurso à metodologia dos por repetitivos leva, então a um duplo julgamento: o do recurso, propriamente, e o da tese a ser aplicada aos todos os casos que versem sobre aquela mesma matéria. Este tem natureza objetiva, ligando-se a interesses difusos de administração da Justiça, tais como a segurança jurídica e a isonomia ${ }^{49}$.

Outro mecanismo no NCPC para lidar com as chamadas macrolides é o incidente de resolução de demandas repetitivas (IRDR, arts. 976/987). A partir da leitura dos requisitos para instauração do IRDR, podemos visualizar, de forma clara, as intenções do instituto: evitar a multiplicação de demandas sobre uma mesma questão de direito, além de garantir a previsibilidade da atuação dos juízes e a igualdade entre os jurisdicionados ${ }^{50}$.

Ademais, outros instrumentos facilitadores, como o banco de dados a que se refere o novo CPC no art. 979, já devidamente regulamentado pela Resolução $\mathrm{n}^{\circ}$ 235/2016 do CNJ conferem maios publicidade e estabilidade ao instituto.

\footnotetext{
${ }^{49}$ TALAMINI, Eduardo. Julgamento de recursos no STJ "por amostragem" - Lei no 11.672/2008. Disponível em <http://www.migalhas.com.br/mostra_noticia_articuladas.aspx?cod=60470>. Acesso em 05/01/2012. Texto originalmente colocado no ar em 15/05/2008.

${ }^{50}$ ROQUE, Andre Vasconcelos. As ações coletivas no direito brasileiro contemporâneo: de onde viemos, onde estamos e para onde vamos?, in Revista Eletrônica de Direito Processual, vol. XII, 2013, pp. 36-65, disponível em www.redp.com.br, acesso em 20 de dezembro de 2013, p. 57.
} 
Revista Eletrônica de Direito Processual - REDP.

Rio de Janeiro. Ano 11. Volume 18. Número 1. Janeiro a Abril de 2017

Periódico Quadrimestral da Pós-Graduação Stricto Sensu em Direito Processual da UERJ

Patrono: José Carlos Barbosa Moreira. ISSN 1982-7636. pp. 278-301

www.redp.uerj.br

Assim sendo, quer nos parecer que já temos a infra-estrutura processual

suficiente para planejar a defesa dos direitos da personalidade por meio da tutela pluri individual. Com isso teremos um grau maior de efetividade, celeridade e uniformidade da decisão judicial.

Nesse passo, não podemos esquecer que os dias atuais trazem severos desafios no que se refere à tutela dos direitos da personalidade e da vida privada.

Nunca estivemos tão vulneráveis em nossa vida pessoal, e tão sujeitos à exposição. Nunca necessitamos tanto de tutela jurídica para tais interesses e incumbe ao Direito a busca por mecanismos que não permitam que eles sejam obliterados. Somente deste modo é possível harmonizar as virtudes do progresso tecnológico com a necessidade de preservar a individualidade humana.

\section{REFERÊNCIAS BIBLIOGRÁFICAS}

BRANDEIS, Louis D.; WARREN, Samuel D. The right to privacy. Harvard Law Review, Cambridge, v. IV, n. 5, 15 dec. 1890. Disponível em: http://readingnewengland.org/app/books/righttoprivacy/?l=righttoprivacy. Acesso em: 27 fev. 2017.

CAPPELLETTI, Mauro. Fundamental guarantees of the parties in civil litigation: comparative constitutional, international, and social trends, in 25 Stanford Law Review, May, 1973, p. 672, acesso via www.westlaw.com, em 15 de março de 2010.

DE CUPIS, Adriano. Os Direitos da Personalidade. Trad. Afonso Celso Furtado Rezende. 2ªd. São Paulo: Quórum, 2008.

DIDIER JR, Fredie. ZANETI JR., Hermes. Ações coletivas e o incidente de julgamento de casos repetitivos - espécies de processo coletivo no direito brasileiro: aproximações e distinções, in Revista de Processo, vol. 256, Jun/2016, pp. 211/212.

FARIAS, Cristiano Chaves de. Direito Civil- Teoria Geral. $9^{\text {a }}$ ed. Rio de Janeiro: Lumen Juris, 2011.

GAGLIANO, Pablo Stolze; FILHO, Rodolfo Pamplona. Novo Curso de Direito Civil, v. 1. $16^{\mathrm{a}}$ ed., São Paulo: Saraiva, 2014. 
Revista Eletrônica de Direito Processual - REDP.

Rio de Janeiro. Ano 11. Volume 18. Número 1. Janeiro a Abril de 2017

Periódico Quadrimestral da Pós-Graduação Stricto Sensu em Direito Processual da UERJ

Patrono: José Carlos Barbosa Moreira. ISSN 1982-7636. pp. 278-301

www.redp.uerj.br

GIDI, Antonio; TESHEINER, José Maria Rosa e PRATES, Marília Zanella. Limites

objetivos da coisa julgada no Projeto de Código de Processo Civil. Reflexões inspiradas na experiência norte-americana. Revista de Processo. vol. 194. São Paulo: Revista dos Tribunais, abr. 2011.

GIDI, Antonio. Class action in Brazil - a model for civil law countries. The American Journal of Comparative Law, v. 51, n. 2, 2003, p. 322.

GRECO, Leonardo. Limitações Probatórias. In: NETTO, Fernando Gama de Miranda; MEIRELLES, Delton Ricardo Soares. Direito Processual em Debate. Niterói: Editora da UFF, 2011.

MANCUSO, Rodolfo de Camargo. Da jurisdição coletiva à tutela judicial plurindividual. Evolução da experiência brasileira com as demandas seriais, in Revista de Processo, vol. 237, nov/2014, p. 310.

MARINONI, Luiz Guilherme. Coisa julgada sobre questão, inclusive em benefício de terceiro, Revista de Processo, vol. 259, São Paulo: Revista dos Tribunais: set/2016.

PINHO, Humberto Dalla Bernardina de. A tutela coletiva no Brasil e a sistemática dos novos direitos. Revista Direito Público, São Paulo v. 2, p. 91-112, 2005.

PINHO, Humberto Dalla Bernardina de. Class actions in Brazilian Law: general aspects. evolution and some controversies. Connecticut Journal of International Law, v. 20, n. 2, 2005, pp. 185/197.

PINHO, Humberto Dalla Bernardina de. Considerações sobre o incidente de conversão da ação individual em ação coletiva no projeto do novo CPC. Revista Eletrônica de Direito Processual, v. XIV, ano 8, jul.-dez. 2014, p. 209.

PINHO, Humberto Dalla Bernardina de. Direito Processual Civil Contemporâneo, vol. 1, 5a edição, São Paulo: Saraiva, 2013.

PINHO, Humberto Dalla Bernardina de. Incidente de Conversão da Ação Individual em Ação Coletiva no CPC Projetado: exame crítico do instituto. Artigo publicado na Revista Eletrônica Processos Coletivos, vol. 4, n 3, $3^{\circ}$ trimestre, p. 23.

RODOTÀ, Stefano. A vida na sociedade da vigilância (org.. Maria Celina Bodin de Moraes). Rio de Janeiro: Renovar, 2008. 
Revista Eletrônica de Direito Processual - REDP.

Rio de Janeiro. Ano 11. Volume 18. Número 1. Janeiro a Abril de 2017

Periódico Quadrimestral da Pós-Graduação Stricto Sensu em Direito Processual da UERJ

Patrono: José Carlos Barbosa Moreira. ISSN 1982-7636. pp. 278-301

www.redp.uerj.br

RODRIGUES, Roberto. Teses Jurídicas Prejudiciais: a ampliação dos limites da coisa julgada enquanto fundamento e técnica otimizadora de julgamentos por amostragem. Tese de Doutorado. UERJ. 2016. 229 f.

ROQUE, Andre Vasconcelos. As ações coletivas no direito brasileiro contemporâneo: de onde viemos, onde estamos e para onde vamos?, in Revista Eletrônica de Direito Processual, vol. XII, 2013, p. 36, disponível em www.redp.com.br, acesso em 20 de dezembro de 2013, p. 41.

ROQUE, Andre Vasconcelos. As ações coletivas no direito brasileiro contemporâneo: de onde viemos, onde estamos e para onde vamos?, in Revista Eletrônica de Direito Processual, vol. XII, 2013, p. 44, disponível em www.redp.com.br, acesso em 20 de dezembro de 2013.

ROQUE, Andre Vasconcelos. As ações coletivas no direito brasileiro contemporâneo: de onde viemos, onde estamos e para onde vamos?, in Revista Eletrônica de Direito Processual, vol. XII, 2013, pp. 36-65, disponível em www.redp.com.br, acesso em 20 de dezembro de 2013.

SARLET, Ingo Wolfgang, MARINONI, Luiz Guilherme, MITIDIERO, Daniel. Curso de Direito Constitucional. $3^{\mathrm{a}}$ ed. São Paulo: RT, 2014.

SCHREIBER, Anderson. Direitos da Personalidade. São Paulo: ATLAS, 2013.

SCHREIBER, Anderson. Os Direitos da Personalidade e o Código Civil de 2002. In: TEPEDINO, Gustavo, FACHIN, Luiz Edson, Diálogos Sobre Direito Civil. Rio de Janeiro: RENOVAR, 2008.

SIQUEIRA, Tatiana Paula Cruz de. A escalada rumo à valorização do precedente judicial no processo civil brasileiro, in CARNEIRO, Paulo Cezar Pinheiro. GRECO, Leonardo. PINHO, Humberto Dalla Bernardina de. Inovações do CPC/2015, GZ: Rio de Janeiro, 2016, p. 67/99.

TALAMINI, Eduardo. Julgamento de recursos no STJ "por amostragem" - Lei n' 11.672/2008. Disponível em <http://www.migalhas.com.br/mostra_noticia_articuladas.aspx?cod=60470>. Acesso em 05/01/2012. Texto originalmente colocado no ar em 15/05/2008. 
Revista Eletrônica de Direito Processual - REDP.

Rio de Janeiro. Ano 11. Volume 18. Número 1. Janeiro a Abril de 2017

Periódico Quadrimestral da Pós-Graduação Stricto Sensu em Direito Processual da UERJ

Patrono: José Carlos Barbosa Moreira. ISSN 1982-7636. pp. 278-301

www.redp.uerj.br

TEIXEIRA, Daniele Chaves. Breves Considerações sobre a privacidade da pessoa notória no espaço público In: TEPEDINO, Gustavo, FACHIN, Luiz Edson. Diálogos sobre direito civil, v. III. Rio de Janeiro: RENOVAR, 2012.

TEPEDINO, Gustavo, et ali. Código Civil Interpretado conforme a Constituição da

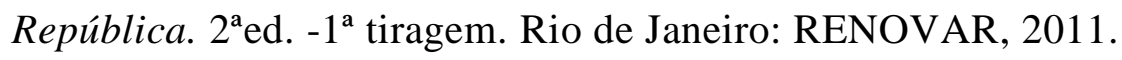

ZANETI Jr., Hermes. Três Modelos de Processo Coletivo no Direito Comparado: Class Actions, Ações Associativas/Litígios Agregados e o "Processo Coletivo: Modelo Brasileiro", in Processos Coletivos, vol. 5, n. 3, jul a set de 2014, disponível em http://www.processoscoletivos.net/, acesso em 15 de março de 2016. 